\section{A) Check for updates}

Cite this: Food Funct., 2019, 10, 1444

\title{
Impact of a sustained consumption of grape extract on digestion, gut microbial metabolism and intestinal barrier in broiler chickens
}

\author{
Susana Chamorro, (D) *a Carlos Romero, (D) ${ }^{\mathrm{b}}$ Agustín Brenes, ${ }^{\mathrm{a}}$ \\ Fernando Sánchez-Patán, ${ }^{c}$ Begoña Bartolomé, ${ }^{c}$ Agustín Viveros ${ }^{d}$ and Ignacio Arija ${ }^{d}$
}

\begin{abstract}
The effect of dietary supplementation with grape extract (GE) at 2.5 and $5.0 \mathrm{~g} \mathrm{~kg}^{-1}$ of feed on intestinal utilization of polyphenols and gut health of broiler chickens was determined. The ileal digestibility of grape polyphenols was higher for flavan-3-ol monomers [(+)-catechin and (-)-epicatechin] than for dimers (Procyanidins B1 and B2) and galloylated compounds [(-)-epicatechingallate] and no differences among 2.5 and $5.0 \mathrm{~g}$ GE per kg dietary treatments were observed. The excreta concentration of benzoic, phenylacetic, phenylpropionic, and cinnamic acids and phenyl- $\gamma$-valerolactone phenolic metabolites was higher in birds fed GE, confirming hence the microbial metabolism of grape polyphenols to a relevant extent. Gut morphology and the total ileal mucin content were not modified by the dietary inclusion of $\mathrm{GE}$, but a lower sialic acid concentration was observed in those birds fed a higher concentration of GE. Escherichia coli and lactic-acid bacteria ileal counts were reduced in birds fed GE. Overall, these results prove the extensive intestinal utilization and microbial metabolism of grape polyphenols in broiler chickens. Some antimicrobial and mucin-modulation effects were also observed after a sustained consumption of grape polyphenols during 21 days.
\end{abstract}

Received 13th December 2018, Accepted 30th January 2019

DOI: $10.1039 / \mathrm{c} 8 \mathrm{fo} 02465 \mathrm{k}$

rsc.li/food-function grape products rich in polyphenols such as GE and grape pomace (GP) obtained from the wine-making industry has been demonstrated as a strategy to enhance the oxidative stability of meat and to promote the proliferation of beneficial intestinal bacteria. ${ }^{3}$ With regard to the mechanism underlying these antioxidant properties, we previously reported a reduction in plasma iron content and an increase in plasma $\alpha$-tocopherol concentration in broiler chickens fed $\mathrm{GE}^{4}$ and $\mathrm{GP}^{5}$

Biological effects of polyphenols depend on their availability, which is highly influenced by the degree of polymerisation. Monomeric flavan-3-ols and some oligomeric procyanidins from GE have been found to be absorbed in the small intestine. $^{6,7}$ However, polymeric forms are poorly absorbed and are further catabolized by the intestinal microbiota into a wide array of low-molecular-weight aromatic acids such as phenylacetic, phenylpropionic, phenylvaleric, and benzoic acid derivatives. $^{8,9}$ These microbial-derived metabolites are more easily absorbed through the intestine, but might also remain in the gut, where they may play a role in the maintenance of intestinal health.

It is widely accepted that, beyond its primary functions in the digestion and absorption of nutrients, intestinal epithelium also plays an important role in controlling the passage of toxins and other metabolites of microbial origin 
towards the bloodstream preventing or mitigating thereby the incidence of digestive diseases. ${ }^{10}$ To maintain the integrity of this defensive barrier, and hence a good health status in the intestine, it becomes important to reduce the impact of microbial injuries to the mucous layer covering the intestinal epithelium. ${ }^{11,12}$ This protective mucous layer is predominantly composed of mucins, glycoproteins rich in threonine and serine synthesized and secreted by goblet cells. Intestinal microbiota has the ability to regulate the synthesis and composition of mucins, as it has been observed in chickens fed dietary probiotics and antibiotic growth promoters. ${ }^{13}$ Other luminal factors such as unabsorbed nutrients might affect as well the amount and type of mucins secreted ${ }^{14}$ by either a direct or indirect manner through the metabolites generated ${ }^{15}$ by intestinal microbiota (e.g. short-chain fatty acids). In this sense, it has been observed that tea catechins led to an increase in the mucin ileal content in rats. ${ }^{16}$ However, studies dealing with the effect of GE consumption on intestinal barrier traits, such as mucin composition and luminal microbial environment, are scanty.

Previous studies by our group using culture-based and molecular approaches indicated that the dietary intake of grape products increases the biodiversity degree of the intestinal microbiota of chickens as well as the antioxidant activity of ileal and excreta contents. ${ }^{17,18}$ A reduction in meat lipid oxidation was also obtained in chickens fed grape products, suggesting therefore that these procyanidins or their metabolites might reach and remain active in tissues. ${ }^{17,19}$

Owing to the increasing interest in evaluating ingredients rich in polyphenols that could be used as dietary supplements in animal and human nutrition, the present study was designed to evaluate the effect of a sustained consumption of grape extract during 21 days on the intestinal health of broiler chickens. For this purpose, in this study we will evaluate: (1) the ileal and excreta digestibility of different grape polyphenolic compounds present in GE, (2) the intestinal microbial metabolites generated with the intake of GE, and (3) the effect of dietary GE on the microbial ecosystem, intestinal structure, and on the mucin type and content.

\section{Materials and methods}

\section{Standards and the tested product}

All solvents used for HPLC analysis were of liquid chromatography grade and the water ultrapure. Standards for catechin (C), epicatechin (EC) and epicatechin-O-gallate (ECG), procyanidin dimer $\mathrm{B} 1$ (PB1) and $\mathrm{B} 2$ ( $\mathrm{PB} 2)$ were purchased from Extrasynthèse (Genay, France). Orcinol and $N$-acetylneuraminic acid were obtained from Sigma-Aldrich (St Louis, MO). Phenolic acid standards used in the study were purchased from Sigma-Aldrich Chemical Co. (St Louis, MO), Phytolab (Vestenbergsgreuth, Germany), or Extrasynthèse (Genay, France). The compound 4-hydroxybenzoic 2,3,5,6-d4 acid, used as the internal standard (IS) for UPLC analysis, was purchased from Sigma-Aldrich Chemical Co. Acetone, butanol, isopro-

panol, hexane, acetonitrile and methanol were obtained from Panreac (Castellar del Vallés, Barcelona, Spain).

The powdered grape extract used (Nor-Grape 80) was purchased from Nor-Feed Sud, Angers (France) and it was obtained with water extraction and spray dried. The main phenolic compounds identified in GE were previously reported: ${ }^{20}$ C (0.84 g per $100 \mathrm{~g})$, EC ( $0.77 \mathrm{~g}$ per $100 \mathrm{~g})$, PB1 (0.68 g per $100 \mathrm{~g})$, PB2 (0.49 g per $100 \mathrm{~g})$, ECG (0.097 g per $100 \mathrm{~g})$, and GA $(0.36 \mathrm{~g}$ per $100 \mathrm{~g})$.

\section{Birds and diets}

A total of 105 one-day-old male broiler Cobb chicks were housed in electrically heated starter batteries in an environmentally controlled room. The chicks were allocated to 21 pens, each pen containing five chicks, to receive three dietary treatments with seven replicates per treatment for 21 days. Diets in mash form and water were provided ad libitum. Experimental diets were as follows: (1) Wheat-soybean control diet (Control), (2) Control $+2.5 \mathrm{~g}$ of GE per $\mathrm{kg}$ of feed and (3) Control $+5 \mathrm{~g}$ of GE per $\mathrm{kg}$ of feed. Celite was added $\left(10 \mathrm{~g} \mathrm{~kg}^{-1}\right.$ of feed) as an indigestible marker (IM) to the three diets. All diets were formulated to meet or exceed the minimum ${ }^{21}$ requirements for broiler chickens and are reported in Table 1. At the end of the experimental period, birds were weighed and the feed consumption was determined. Experimental procedures were approved by the University Complutense of Madrid Animal Care and Ethics Committee in compliance with the Ministry of Agriculture, Fishery and Food guidelines for the Care and Use of Animals for Scientific Purposes.

Table 1 Ingredients and nutrient composition of the control diet ( $\mathrm{g} \mathrm{kg}^{-1}$ as fed)

\section{Item}

Control diet

\section{Ingredients}

Wheat ( $12 \%$ crude protein)

Soybean ( $47 \%$ crude protein)

Sunflower oil

Monocalcium phosphate

Calcium carbonate

Salt

Vitamin-mineral premix ${ }^{a}$

DL-methionine

Analysed composition

Crude protein

Lysine

Methionine

Cystine

Threonine

Calculated composition

$\mathrm{AME}^{b}\left(\mathrm{kcal} \mathrm{kg}^{-1}\right)$

$\mathrm{Ca}$

Available P

534.0

341.0

86.0

13.0

17.0

3.0

5.0

1.0

210.0

13.57

3.79

2.93

9.11

3.050

10.0

4.5

${ }^{a}$ Vitamin and mineral mix supplied the following per kilogram of diet: vitamin A, 8250 IU; cholecalciferol, $1000 \mathrm{IU}$; vitamin E, 11 IU; vitamin $\mathrm{K}, 1.1 \mathrm{mg}$; vitamin B12, $12.5 \mu \mathrm{g}$; riboflavin, $5.5 \mathrm{mg}$; Ca panthotenate, $11 \mathrm{mg}$; niacin, $53.3 \mathrm{mg}$; choline chloride, $1020 \mathrm{mg}$; folic acid, $0.75 \mathrm{mg}$; biotin, $0.25 \mathrm{mg}$; ethoxiquin, $125 \mathrm{mg}$; DL-methionine, $500 \mathrm{mg}$; amprol, $1 \mathrm{~g}$; Mn, 55 mg; Zn, 50 mg; Fe, 80 mg; Cu, 5 mg; Se, 0.1 mg; I, 0.18 mg; $\mathrm{NaCl}, 2500 \mathrm{mg} .{ }^{b}$ AME: apparent metabolisable energy. 


\section{Sample collection and measurements}

At the 20th day, clean stainless steel collection trays were placed under each pen for collecting birds excreta for the next $24 \mathrm{~h}$. Fresh excreta was collected per pen, placed in polyethylene bags and freeze-dried for the subsequent determination of IM, grape polyphenols (GPol) and their microbial-derived metabolites.

At 21 days of age, 15 birds per dietary treatment were randomly taken and euthanized using carbon dioxide and used for evaluating ileal polyphenol digestibility and changes in the mucin composition. The ileal contents of 3 birds out of the 15 were pooled to give 5 replicates per treatment. Pooled samples were then frozen, freeze-dried, ground ( $1 \mathrm{~mm}$ screen) and subsequently analysed for phenolic compounds and IM. In these ileal samples, mucins were extracted to determine their sialic acid concentration. Another 14 birds per treatment (7 replicates, 2 birds per replicate) were used for microbial analyses and jejunal morphology study. Fresh ileal contents from two birds (7 replicates/treatment) were aseptically removed and pooled. Then, ileal digesta was placed in sterilized plastic tubes to determine anaerobic (Lactobacillus and Clostridium) and aerobic (Escherichia coli and Enterobacteriaceae) colonyforming bacteria. In those same birds, $5 \mathrm{~cm}$ of the jejunum were taken to perform the gut morphology studies (villus height, crypt depth and goblet cells count). Tissues samples were placed in $4 \%$ formalin in $0.1 \mathrm{M}$ phosphate buffer $(\mathrm{pH}=$ 7.0) for fixation.

\section{Polyphenolic content}

The polyphenolic content was determined in GE, ileal and excreta samples after extraction with methanol/acetone/ water. $^{20}$ Concentrations of phenolic compounds in the GE, ileal and excreta samples were analysed by HPLC-MS. An Agilent 1100 series LC, comprised of a quaternary pump with an integrated degasser, autosampler, thermostated column compartment and diode array detector (DAD), coupled with an Agilent G1946D Quadrupole mass spectrometer (Agilent Technologies, Waldbroon, Germany) was used. Ten microlitres of filtered samples were separated in a Gemini C18 $5 \mu \mathrm{m}$ $250 \mathrm{~mm} \times 4.6 \mathrm{~mm}$ i.d. column (Phenomenex) and eluted with a mobile phase made of a mixture of deionized water and acetonitrile, both containing $0.1 \%$ formic acid, at a flow rate of $1 \mathrm{~mL} \mathrm{~min}^{-1}$. Ionization was achieved with an atmospheric pressure electrospray ionization (ESI) source, operated in the negative ion mode. The selected ion monitoring (SIM) scan type was used for quantification. Data acquisition and analysis were carried out with Agilent ChemStation Software. Phenolic yields were expressed as mg per $100 \mathrm{~g}$ DM.

\section{Microbial-derived phenolic metabolites}

Concentrations of microbial-derived metabolites in the freezedried excreta samples were determined by UPLC-DAD-ESI-TQ MS. $^{22}$ Before the analysis, samples were weighed $(0.5 \mathrm{~g})$ in $50 \mathrm{~mL}$ sterile conical tubes. Five milliliters $(5 \mathrm{~mL})$ of sterile saline solution (NaCl, 0.9\%; Fresenius Kabi, Spain) were added prior to vortexing and storing the preparation in the fridge for hydration. Samples were then centrifuged (10 min, $1000 \mathrm{rpm}$, $4{ }^{\circ} \mathrm{C}$ ) and the supernatant collected in $2 \mathrm{~mL}$ aliquots. Then, they were diluted $1: 2$ with acetonitrile/water $(2: 4, \mathrm{v} / \mathrm{v})$ and filtered $(0.22 \mu \mathrm{m})$. Samples $(190 \mu \mathrm{L})$ were spiked $(10 \mu \mathrm{L})$ with a stock IS solution $\left(50 \mu \mathrm{g} \mathrm{mL^{-1 }}\right.$ in acetonitrile/water $\left.(1: 4, \mathrm{v} / \mathrm{v})\right)$ to achieve a final IS concentration of $2.5 \mu \mathrm{g} \mathrm{mL}{ }^{-1}$. An UPLC system, coupled to an Acquity PDA photodiode array detector and an Acquity TQD tandem quadrupole mass spectrometer equipped with the Z-spray electrospray interface (UPLCDAD-ESI-TQ MS) (Waters, Milford, MA, USA), was used. Separation $(2 \mu \mathrm{l})$ was performed on a Waters_BEH C18 column $(2.1 \times 100 \mathrm{~mm} ; 1.7 \mu \mathrm{m})$ at $40{ }^{\circ} \mathrm{C}$. A gradient, composed of solvent A-water : acetic acid $(98: 2, \mathrm{v} / \mathrm{v})$ and B-acetonitrile : acetic acid $(98: 2, \mathrm{v} / \mathrm{v})$, was applied at flow rate of $0.5 \mathrm{~mL} \mathrm{~min}^{-1}$ as follows: $0-1.5 \mathrm{~min}: 0.1 \% \mathrm{~B}, 1.5-11.17 \mathrm{~min}: 0.1-16.3 \% \mathrm{~B}$, 11.17-11.5 min: $16.3-18.4 \% \mathrm{~B}, \mathbf{1 1 . 5}-14 \mathrm{~min}: 18.4 \% \mathrm{~B}$, 14-14.1 min: $18.4-99.9 \% \quad \mathrm{~B}, \quad \mathbf{1 4 . 1}-15.5 \mathrm{~min}: 99.9 \% \mathrm{~B}$, 15.5-15.6 min: $0.1 \% \mathrm{~B}, 15.6-18 \mathrm{~min}: 0.1 \% \mathrm{~B}$. The DAD was operated in the $250-420 \mathrm{~nm}$ wavelength range at a 20 point/s rate and $1.2 \mathrm{~nm}$ resolution. The ESI parameters were: capillary voltage, $3 \mathrm{kV}$; source temperature, $130{ }^{\circ} \mathrm{C}$; desolvation temperature, $400{ }^{\circ} \mathrm{C}$; desolvation gas $\left(\mathrm{N}_{2}\right)$ flow rate, $750 \mathrm{~L} \mathrm{~h}^{-1}$; cone gas $\left(\mathrm{N}_{2}\right)$ flow rate, $60 \mathrm{~L} \mathrm{~h}^{-1}$. The ESI was operated in the negative mode, except for c-valerolactone which was operated in the positive mode. For quantification purposes, data were collected in the multiple reaction monitoring (MRM) mode, tracking the transition of parent and product ions specific for each compound and using external calibration curves. MRM transitions were those described for microbial phenolic metabolites. $^{22,23}$ Data acquisition (and processing) was carried out using MassLynx 4.1 software.

\section{Intestinal digestibility of grape polyphenols}

The IM (Celite) was analysed in feed, ileal content and excreta. Celite, a source of acid insoluble ash, was measured after ashing the samples and treating the ashes with boiling $4 \mathrm{M}$ HCL. $^{24}$

The apparent ileal and excreta digestibility of grape polyphenols (GPol) was calculated with the following formula:

$$
\begin{aligned}
& 100-[100 \times((\text { IM in feed } / \mathrm{IM} \text { in digesta }) \\
& \times(\text { GPol in digesta/GPol in feed }))]
\end{aligned}
$$

\section{Microbiological analyses}

One gram of the ileal content was blended with $9 \mathrm{~mL}$ of peptone water. All blended samples were vortexed and further diluted tenfold down to $10^{-10}$ dilution. The first six dilutions were plated to enumerate Clostridium perfringens, Escherichia coli and Enterobacteriaceae whereas only $10^{-7}, 10^{-8}, 10^{-9}$ and $10^{-10}$ dilutions were plated for lactic-acid bacteria enumeration. Clostridium perfringens enumeration was performed according to the Standard 7937 (ISO, 1997). This technique analyses all the toxinotypes of Clostridium perfringens. The cultural medium was agar tryptose sulfite added with antibiotic D-cycloserine. Agar plates were incubated at $37^{\circ} \mathrm{C}$ in anaerobic 
jars for 18 h. Escherichia coli counts were determined following the Standard 9001 (ISO, 2000) by using the $3 \mathrm{M}^{\mathrm{TM}}$ Petrifilm ${ }^{\mathrm{TM}}$ E. coli/coliform count plate. The culture medium system contained Violet Red Bile nutrients, an indicator of glucuronidase activity and 5-bromo-4-chloro-3-indolyl-beta-D-glucoronide (BCIG). The 3M Petrifilm Enterobacteriaceae count plate was used for Enterobacteriaceae enumeration according to the Standard 9002 (ISO, 1994). The culture medium system contained modified Violet Red Bile Glucose nutrients. The latter Petrifilm plates also contained a cold-water-soluble gelling agent and a tetrazolium indicator that facilitated colony enumeration. All plates were incubated for $24 \mathrm{~h}$ at $37^{\circ} \mathrm{C}$. The enumeration of lactic-acid bacteria was performed following the Standard 15214 (ISO, 1998), plates were incubated in MRS (Man, Rogosa and Sharp, Merck, Germany) agar for $72 \mathrm{~h}$ at $30{ }^{\circ} \mathrm{C}$. After incubation, all colonies appearing on agar and Petrifilm plates were observed and counted.

\section{Intestinal mucins and morphology}

Crude mucin was analyzed in freeze-dried samples of the ileal content $^{25}$ with some modifications. ${ }^{26,27}$ The sialic acid concentration was determined from the purified crude mucin samples according to the ferric orcinol assay. ${ }^{28}$

The jejunal samples were processed for $24 \mathrm{~h}$ in a tissue processor with ethanol as the dehydrant and samples were embedded in paraffin. Sections $(5 \mu \mathrm{m})$ were made from the tissue and were stained with hematoxylin-eosin and a combination of the periodic acid-Schiff method (PAS staining). Histological sections were examined with a light microscope (Olympus BX40, Olympus Optical Co., Hamburg, Germany) to determine their morphometric index by computer-assisted image analysis (The ImageJ v 1.26. Wayne Rasband, National Institutes of Health, Bethesda, Maryland, USA). The variables measured were villus height, crypt depth and goblet cell number. A minimum of 10 intact well-oriented villus-crypt units were selected for each intestinal cross-section. Villus height $(\mu \mathrm{m})$ was measured from the tip to the villus crypt junction, and crypt depth was defined as the depth of the invagination between adjacent villi. The number of stained goblet cells per villi was also counted.

\section{Statistical analysis}

Data were analysed as a one-way ANOVA using the GLM procedure of SAS. ${ }^{29}$ The linear effect of dietary inclusion of GE was also analysed. Significant differences among treatment means were determined at $P<0.05$ by Duncan's multiple-range test.

\section{Results}

\section{Content and intestinal digestibility of grape polyphenols}

Concentrations of monomeric and dimeric flavan-3-ols in ileal digesta and excreta of birds fed 2.5 and $5.0 \mathrm{~g}$ of GE per $\mathrm{kg}$ of feed are reported in Table 2 . The ileal concentration of every compound studied was increased with the higher dietary supplementation of GE; C, EC, PB1 and PB2 ileal contents increased $(P<0.001)$ by $65,83,35$ and $63 \%$, respectively. The same result, albeit at a lower extent, was observed for C $(24 \%$, $P<0.001)$, EC $(34 \%, P<0.01)$ and PB1 $(5 \%, P<0.05)$ excreta concentrations. Based on these concentrations, data of apparent digestibility of these compounds were calculated (Fig. 1). The ileal digestibility of monomeric compounds ( $C$ and EC) reached values in the range of $84-87 \%$ in birds fed the GE diets. However, the digestibility of PB1 and PB2, and that of ECG were lower and ranged from 50 to $69 \%$. For all these polyphenolic compounds, values for excreta digestibility were higher than those for ileal digestibility. No differences on ileal and excreta digestibility among 2.5 and $5.0 \mathrm{~g}$ GE per kg dietary treatments were observed.

\section{Phenolic metabolites in excreta}

A total of 22 phenolic metabolites including benzoic, phenylacetic, phenylpropionic and cinnamic acids, as well as phenyl$\gamma$-valerolactones, were identified in the excreta samples of the chickens in the present work (Table 3). Among these phenolic acids, 3,4,5-trihydroxybenzoic acid, 5-(3',4'-dihydroxyphenyl-)$\gamma$-valerolactone and m-hydroycinnamic acid were only identified in the excreta of chickens having been supplemented with GE. Likewise, the excreta concentrations of 2-hydroxybenzoic, 3-O-methylgallic, 4-O-methylgallic, 3-(4-hydroxyphenyl) propionic, and 3,4-dihydroxycinnamic acids were found to be higher

Table 2 Quantification of phenolic compounds recovered in ileal digesta and excreta ( $\mathrm{mg}$ per $100 \mathrm{~g}$ ) from chicks supplemented with grape extract (GE; 2.5 and $5 \mathrm{~g} \mathrm{~kg}^{-1}$ of feed)

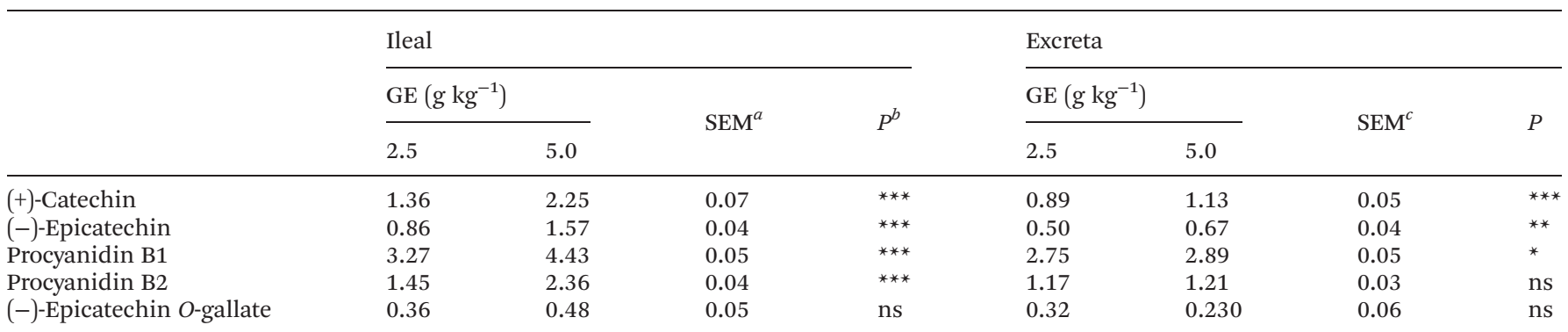

${ }^{a} n=5$ replicates (3 birds per replicate). ${ }^{b}$ Type of response due to dietary dose of GE: ns, no significant effect, ${ }^{*} P<0.05 ;{ }^{* *} P<0.01 ;{ }^{* * *} P<0.001$. ${ }^{c} n=7$ replicates ( 5 birds per replicate). 


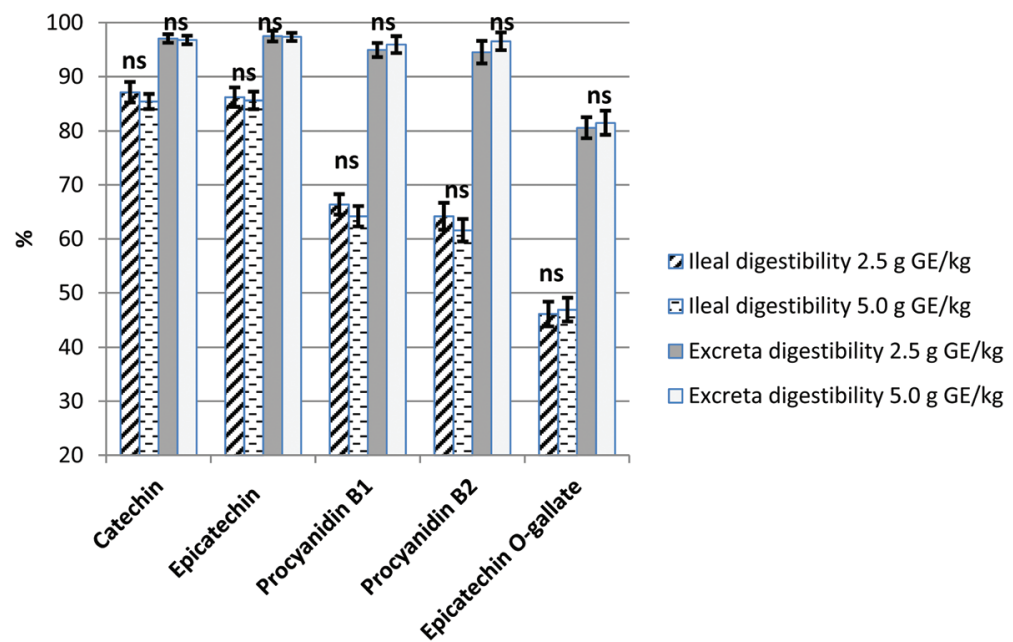

Fig. 1 Ileal and excreta digestibility (\%) of polyphenols in chickens fed 2.5 and $5 \mathrm{~g} \mathrm{~kg}^{-1}$ of grape extract (GE). Data are means \pm standard deviation of 5 replicates per treatment (three birds per replicate) for ileal digestibility and 7 replicates per treatment (five birds per replicate) for excreta digestibility. No significant differences (ns) among treatments were considered when $P>0.05$.

Table 3 Microbial-derived phenolic metabolites $\left(\mu \mathrm{g} \mathrm{g}^{-1}\right)$ in excreta from chickens fed diets containing grape extract (GE)

\begin{tabular}{|c|c|c|c|c|c|c|}
\hline & \multicolumn{3}{|c|}{$\mathrm{GE}\left(\mathrm{g} \mathrm{kg}^{-1}\right)$} & $\mathrm{SEM}^{a}$ & \multicolumn{2}{|l|}{$P^{b}$} \\
\hline 2-Hydroxybenzoic (salicylic) acid & $0.11^{\mathrm{b}}$ & $0.79^{\mathrm{a}}$ & $0.68^{\mathrm{a}}$ & 0.15 & ** & ns \\
\hline 3-Hydroxybenzoic acid & 11.0 & 9.12 & 9.55 & 1.59 & ns & ns \\
\hline 4-Hydroxybenzoic acid & $29.3^{\mathrm{a}}$ & $24.0^{\mathrm{b}}$ & $23.6^{\mathrm{b}}$ & 1.11 & ** & ** \\
\hline 3,4-Dihydroxybenzoic (protocatechuic) acid & 14.7 & 16.1 & 14.5 & 1.51 & ns & ns \\
\hline 3-O-Methylgallic acid & $1.95^{\mathrm{b}}$ & $3.59^{\mathrm{a}}$ & $3.99^{\mathrm{a}}$ & 0.55 & * & * \\
\hline 4-O-Methylgallic acid & $0.03^{\mathrm{c}}$ & $1.61^{\mathrm{b}}$ & $2.95^{\mathrm{a}}$ & 0.29 & *** & *** \\
\hline 4-Hydroxy-3-methoxybenzoic (vanillic) acid & 11.1 & 12.0 & 9.85 & 0.99 & ns & ns \\
\hline \multicolumn{6}{|l|}{ Phenylacetic acids } & ns \\
\hline 3-Hydroxyphenylacetic acid & 6.08 & 6.02 & 6.20 & 0.94 & ns & ns \\
\hline 4-Hydroxyphenylacetic acid & 112 & 101 & 106 & 17.1 & ns & ns \\
\hline 3-(3-Hydroxyphenyl)propionic acid & 79.7 & 126 & 96.0 & 20.1 & ns & ns \\
\hline 3-(4-Hydroxyphenyl)propionic acid & $35.3^{\mathrm{c}}$ & $123^{\mathrm{a}}$ & $60.9^{\mathrm{b}}$ & 4.20 & $* * *$ & ns \\
\hline Phenyl- $\gamma$-valerolactones & & & & & & \\
\hline 5 -(3', $4^{\prime}$-Dihydroxyphenyl-)- $\gamma$-valerolactone & nd & 0.37 & 1.38 & 0.53 & ns & ns \\
\hline Cinnamic acids & & & & & & \\
\hline p-Hydroxycinnamic (coumaric) acid & 12.1 & 11.3 & 11.7 & 1.14 & ns & ns \\
\hline$m$-Hydroxycinnamic (coumaric) acid & nd & 0.16 & 0.08 & 0.06 & ns & ns \\
\hline 3,4-Dihydroxycinnamic (caffeic) acid & $1.60^{\mathrm{b}}$ & $3.15^{\mathrm{a}}$ & $4.0^{\mathrm{a}}$ & 0.43 & $* *$ & $* *$ \\
\hline 4-Hydroxy-3-methoxycinnamic (ferulic) acid & $11.3^{\mathrm{a}}$ & $8.74^{\mathrm{b}}$ & $8.72^{\mathrm{b}}$ & 0.66 & * & ** \\
\hline
\end{tabular}

${ }^{\mathrm{a}, \mathrm{b}, \mathrm{c}}$ Means in a row with a different superscript differ $(P<0.05) .{ }^{a} n=7$ replicates ( 5 birds per replicate). ${ }^{b}$ Type of response due to dietary dose of GE: ns, no significant effect, ${ }^{*} P<0.05 ;{ }^{* *} P<0.01 ;{ }^{* *} P<0.001$. nd: no detected.

$(P<0.05)$ in chickens fed GE than in those not being supplemented with GE. A linear increase $(P<0.05)$ was also detected for the excreta concentration of 3-O-methylgallic, 4-Omethylgallic, and 3,4-dihydroxycinnamic acids.
By contrast, the intake of GE reduced $(P<0.05)$ the excreta content of 4-hydroxybenzoic, 2-hydroxy-2-phenylacetic and 4-hydroxy-3-methoxycinnamic acids, and a linear response $(P<0.01)$ was also detected for the latter acids. 


\section{Microbiological analysis}

The effect of including GE in the diet on ileal bacterial counts is summarized in Table 4. Escherichia coli and lactic-acid bacteria counts were decreased $(P<0.05$ and $P<0.01$, respectively) in birds fed $5 \mathrm{~g}$ GE per $\mathrm{kg}$ of diet. A decreasing linear response $(P<0.05)$ with the intake of GE was also detected for these bacteria and for Enterobacteriaceae. No differences were found in the ileal populations of Clostridium perfringens among dietary treatments.

\section{Intestinal mucins and gut morphology}

The effect of dietary GE on total mucin and sialic acid content in ileal digesta and on jejunal morphology is reported in Table 5. Total mucin content (3.58 $\mathrm{g}$ DM per $100 \mathrm{~g}$ of dry ileal digesta, on average) was not significantly modified by the inclusion of GE in the diet. A reduction $(P<0.05)$ in the sialic acid content and a linear response $(P<0.01)$ were observed with the intake of GE.

No effect of GE inclusion in the diet was detected on villus height or crypt depth. The jejunal goblet cell number was not affected by the dietary inclusion of GE.

Table 4 Effect of dietary inclusion of grape extract (GE) on the ileal bacterial count expressed as the logarithm of colony-forming units per gram (log cfu per g)

\begin{tabular}{|c|c|c|c|c|c|c|}
\hline & \multicolumn{3}{|c|}{$\mathrm{GE}\left(\mathrm{g} \mathrm{kg}^{-1}\right)$} & \multirow[b]{2}{*}{$\operatorname{SEM}^{a}$} & \multicolumn{2}{|l|}{$P^{b}$} \\
\hline & 0 & 2.5 & 5 & & Diet & Linear \\
\hline Clostridium perfringens & 4.03 & 4.46 & 4.46 & 0.39 & ns & ns \\
\hline Escherichia coli & $6.02^{\mathrm{a}}$ & $5.11^{\mathrm{ab}}$ & $4.85^{\mathrm{b}}$ & 0.34 & * & * \\
\hline Enterobacteriaceae & 6.36 & 5.92 & 5.48 & 0.38 & ns & * \\
\hline Lactic-acid bacteria & $7.58^{\mathrm{a}}$ & $7.19^{\mathrm{ab}}$ & $6.77^{\mathrm{b}}$ & 0.19 & ** & ** \\
\hline
\end{tabular}

${ }^{a} n=7$ replicates ( 2 birds per replicate). ${ }^{b}$ Type of response due to dietary dose of GE: ns, no significant effect, ${ }^{*} P<0.05 ;{ }^{* *} P<0.01$. ${ }^{\mathrm{a}, \mathrm{b}}$ Means in a row with different superscript differ $(P<0.05)$.

Table 5 Effect of dietary grape extract (GE) on the total mucin and sialic acid content in ileal digesta of chicks and jejunal morphology

\begin{tabular}{|c|c|c|c|c|c|c|}
\hline & \multicolumn{3}{|c|}{$\mathrm{GE}\left(\mathrm{g} \mathrm{kg}^{-1}\right)$} & \multirow[b]{2}{*}{ SEM } & \multicolumn{2}{|l|}{$P^{c}$} \\
\hline & 0 & 2.5 & 5.0 & & Diet & Linear \\
\hline \multicolumn{7}{|l|}{ Ileal mucin content ${ }^{a}$} \\
\hline $\begin{array}{l}\text { Total mucin ( } \mathrm{g} \text { DM per } \\
100 \mathrm{~g} \text { ) }\end{array}$ & 3.64 & 3.55 & 3.55 & 0.12 & ns & ns \\
\hline $\begin{array}{l}\text { Sialic acid (mg per } \\
100 \mathrm{~g})\end{array}$ & $31.7^{\mathrm{a}}$ & $26.8^{\mathrm{ab}}$ & $20.2^{\mathrm{b}}$ & 2.61 & * & ** \\
\hline \multicolumn{7}{|l|}{ 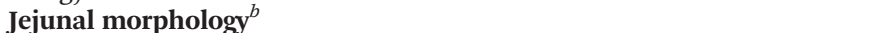 } \\
\hline Villus height, $\mu \mathrm{m}$ & 1116 & 1097 & 1106 & 61.8 & ns & ns \\
\hline Crypt depth, $\mu \mathrm{m}$ & 170 & 177 & 176 & 12.3 & ns & ns \\
\hline Goblet cell number & 100 & 114 & 86 & 12.1 & ns & ns \\
\hline
\end{tabular}

${ }^{a} n=5$ replicates ( 3 birds per replicate). ${ }^{b} n=7$ replicates ( 2 birds per replicate). ${ }^{c}$ Type of response due to dietary dose of GE: ns, no significant effect, ${ }^{*} P<0.05 ;{ }^{* *} P<0.01$. ${ }^{\mathrm{a}, \mathrm{b}}$ Means in a row with different superscript differ $(P<0.05)$.

\section{Discussion}

\section{Intestinal utilization of grape polyphenols}

Polyphenols are considered anti-nutritional factors as the dietary incorporation of ingredients rich in tannins negatively affects nutrient efficiency and animal performance. In poultry, a considerable number of publications have shown the detrimental effect of a relatively high dietary inclusion of ingredients such as sorghum and faba bean. ${ }^{30-32}$ However, current scientific evidence suggests that the dietary addition of moderate amounts of ingredients and additives containing certain classes of phenolic compounds might improve health status and animal product quality without compromising productive performance. Actually, the interest of including grape polyphenols in animal diets has recently been reviewed. ${ }^{3}$ The inclusion of different commercial grape extracts in broiler chicken diets enhanced the oxidative stability of meat and promoted the proliferation of beneficial intestinal bacteria. ${ }^{18,33}$ However, although GE was not detrimental when fed at $3.6 \mathrm{~g} \mathrm{~kg}^{-1}$, its dietary addition at $7.2 \mathrm{~g} \mathrm{~kg}^{-1}$ reduced the weight gain by $12 \% .{ }^{18}$ Thus, in order to establish the optimal and practical inclusion level, in the present experiment we determined the highest concentration of GE that could be included in the chicken diet without affecting the growth performance and nutrient digestibility, as reported in a previous paper. ${ }^{4}$ Our results showed that the dietary incorporation of GE up to $2.5 \mathrm{~g} \mathrm{~kg}^{-1}$ in chicken diets did not affect the growth performance, whereas a dose of $5 \mathrm{~g} \mathrm{~kg}^{-1}$ impaired the growth rate (by $5 \%$ ) and digestibility of some essential and non-essential amino acids, with a particularly marked reduction for proline. In order to assess the impact of GE intake on intestinal health and correctly identify the microbial metabolites generated in the gut, in the present study we focused on the treatments presenting the higher doses of GE (2.5 and $\left.5 \mathrm{~g} \mathrm{~kg}^{-1}\right)$. The negative effect of feeding polyphenols on the digestibility of some nutrients, such as fat, protein and amino acids, has been widely addressed $^{30,34}$ but few studies have reported information about the rate of intestinal utilization of grape polyphenols themselves. In this sense, previous research conducted in our laboratory with chickens fed diets containing $\mathrm{GE}^{17,33}$ showed a digestibility rate lower for non-extractable (14-47\%) than for total extractable (58-66\%) and hydrolizable (56-73\%) fractions. With regard to human studies, there are also many references in the literature, ${ }^{35,36}$ dealing with the composition and potential health benefits of grape polyphenols but there is a dearth of in vivo studies tackling the intestinal utilization of these bioactive substances. ${ }^{37,38}$

In the present study, we use the term digestibility, commonly used in animal nutrition, referring to the fraction of ingested grape polyphenolic compounds that disappear in the intestine, as a consequence of the digestive processes, and are potentially degraded, biotransformed or absorbed through the gut barrier. This term is equivalent to "disappeared ratio" and does not account for the metabolites generated and effluxed back into the intestinal lumen after intestinal and hepatic metabolism. Our findings indicate that, irrespective of the con- 
centration of GE included in the diet, extractable grape catechins disappeared extensively and/or were chemically modified along the intestinal tract, which led in consequence to a low recovery of these compounds. The digested fractions were higher for monomers, than for dimers, and galloylated forms. It was thus proved that the degree of polymerization and galloylation are factors affecting the intestinal utilization of flavan-3-ols. ${ }^{39,40}$ We recently reported ${ }^{5}$ similar monomeric and dimeric digestibility values for catechins present in grape pomace.

Due to their lower molecular weights and the fewer hydrogen bond donors in $\mathrm{C}$ and EC, these compounds are expected to be better used than the galloylated forms. In human subjects with an ileostomy, ${ }^{37,38,41}$ similar low recoveries of ileal native monomerics C and EC (6.8-2.3\% and $4.2-11 \%$, respectively) and dimeric PB (22\%) have been detected after the consumption of tea and fruit drinks containing polyphenols during 24 hours. Likewise, a higher recovery of the galloylated form of epicatechin (ECG, 45\%) has also been reported. Another human study based on the use of the intestinal perfusion technique ${ }^{42}$ showed a recovery of $46.8 \%$ for EC and of $1.7 \%$ for EC metabolites after the administration of $50 \mathrm{mg}$ of pure EC into the proximal jejunum. All these studies agree that, regardless of the differences in the intestinal model used (ileostomy, perfusion, indigestible marker), the administration (acute or sustained consumption), the dose or the food matrix, ingested (not metabolized) catechins are recovered at a low concentration in the intestinal tract. Despite this limited recovery, a low bioavailability of grape polyphenols has also been reported in studies encompassing absorption and metabolism traits. ${ }^{7,37}$ In this sense, in the ileostomy studies mentioned above, a high ileal and urine recovery of (epi) catechin metabolites (glucuronided and sulfated) was also detected, reflecting hence an important reexcretion of intestinal and hepatic metabolites, which were not taken into account in the present study.

Polyphenols not being absorbed or being effluxed back in the intestine are further metabolized by the intestinal microbiota into phenolic acids and other metabolites. ${ }^{43}$ This might contribute to explain why, in the present study, the excreta digestibility of grape polyphenols was higher than the ileal digestibility. There is an emerging consensus that the gut microbiota may play a crucial role in the potential health benefits of polyphenols. ${ }^{44,45}$ The microbiota present in the intestinal tract could metabolize dietary polyphenols into more bioactive compounds with different physiological significance. ${ }^{46}$ In this study, we identified a wide range of low-molecular-weight phenolic compounds in the excreta of all birds, either supplemented or not with GE. The latter may be related to the fact that experimental diets contained wheat and soya as main ingredients, which are also important sources of phenolic compounds. ${ }^{47}$ Nevertheless, when comparing the excreta metabolites of birds fed control and GE diets, we observed differences in the amount and nature of the phenolic compounds identified, as a consequence of the GE intake. By examining these metabolites, we present here the first evi- dence in poultry that grape polyphenols are degraded during their transit along the intestinal tract. Benzoic acids (3,4,5-trihydroxybenzoic or gallic acid, 2-hydroxybenzoic, 3-O-methylgallic and 4-O-methylgallic acids), propionic acids [3-(3-hydroxyphenyl) propionic and 3-(4-hydroxyphenyl) propionic acids], cinnamic acids (3,4-dihydroxycinnamic acid), as well as valerolactones derivatives [5-(3', $4^{\prime}$-dihydroxyphenyl-)- $\gamma$-valerolactone $]$, were found as the most relevant metabolites in the excreta of chickens supplemented with GE. Among them, gallic acid, m-coumaric acid and valerolactone derivatives were exclusively detected in birds fed GE, with the latter being one of the major metabolites generated during the microbial metabolism of procyanidin dimers. ${ }^{48}$ The microbial origin of these metabolites has been demonstrated by the in vitro incubation of procyanidins with the rat caecal content ${ }^{49}$ and human faecal microflora. ${ }^{9,22,50,51}$ Similar results have also been obtained in the faeces and urine of rats that had been fed dimeric, trimeric and polymeric procyanidins. ${ }^{8,52,53}$ Other phenolic metabolites with increased concentrations were 3-(3,4-dihydroxyphenyl)propionic acid, 3,4-dihydroxyphenylacetic acid, 4-hydroxyhippuric acid, hippuric acid, and vanillic acid. Most of these metabolites are known to originate from the gut microbial fermentation of wine and grape polyphenols. ${ }^{22,54,55}$ The biological activities of these microbial metabolites have not been systematically tested, except for a few reports in which products of the colonic degradation of flavonoids exhibited anti-inflammatory effects and antioxidant activity. ${ }^{56,57}$ These aromatic acids might exert a protection against oxidative stress and account for some of the biological effects reported for proanthocyanidins and other high-molecular-weight polyphenols in animal and human studies. Many of these phenolic compounds can be absorbed and may accomplish their action in the colon, as well as in other target tissues, after absorption. Finally, our findings indicate that an important proportion of ingested grape polyphenols are metabolized along the intestinal tract and might contribute to explain the antioxidant effect demonstrated in chickens. ${ }^{19}$

\section{Grape polyphenols and intestinal microbiota}

In recent years, the interest in studying interactions between polyphenols and gut microbiota has increased. ${ }^{58-60}$ Polyphenols and their derived products might affect intestinal ecology by accumulation in the gut of undigested and unabsorbed compounds and phenol metabolites that stimulate and/or suppress the growth of certain members of the intestinal microbiota. Thus, in the present study we focused on the effect of GE dietary supplementation on several bacterial species relevant for intestinal health in chickens. Our results indicated that birds fed GE diets showed a reduction in the ileal counts of Escherichia coli, Enterobacteriaceae and lactic bacteria, whereas no response was observed for Clostridium perfringens. The antimicrobial activity of red wine grape pomace and grape seed extract against several pathogenic bacteria such as E. coli, Salmonella spp., among others, has also been documented. ${ }^{61,62}$ In vitro studies have pointed out the potential of catechins and its metabolites to inhibit the growth 
of Clostridium difficile, E. coli and Salmonella. ${ }^{63,64}$ However, other groups such as probiotic-like bacteria Lactobacillus spp. were found to be relatively unaffected or even stimulated. ${ }^{65}$ Moreover, in vivo studies have also demonstrated the potential of grape products to modify the intestinal microbial composition. ${ }^{66}$ Thus, the addition of grape products in diets for pigs reduced E. coli-induced diarrhoea and decreased the counts of Streptococcus spp. and Clostridium in the faecal microbiota, ${ }^{67,68}$ whereas feeding a diet supplemented with GE (0.15-0.45 $\mathrm{g} \mathrm{kg}^{-1}$ ) to broiler chickens reduced ileal coliforms and E. coli populations. ${ }^{69}$ On the other hand, grape polyphenols might also promote the growth of several bacteria groups as we previously reported ${ }^{18}$ using T-RFLP techniques. In this sense, we observed a larger biodiversity and a higher frequency of detection of some known groups (Actinobacteria, Bacillus/ Paenibacillus spp., Desulfitobacterium spp., Pseudomonas/ Acinetobacter spp.), but also, and mainly, of unknown bacteria groups in birds fed grape polyphenols. The intestinal ecosystem of chickens remains largely unknown, and despite the advances made in the field of microbial metabolism of phenolics compounds in humans ${ }^{60}$ the specific bacterial species able to metabolize grape polyphenols in the gastrointestinal tract of chickens, the intermediate products and the enzymes involved are yet to be elucidated.

\section{Grape polyphenols and intestinal barrier mechanisms}

The mucous layer and the amount and type of mucins that cover and protect the intestinal epithelium might be affected by luminal factors such as unabsorbed nutrients ${ }^{25}$ and metabolites generated by intestinal microbiota. Our results indicate that supplementation with GE, irrespective of the inclusion rate, did not affect the crude ileal mucin content or the jejunal goblet cells number. Nevertheless, the addition of graded concentrations of GE in the chicken diets caused a linear decrease in the ileal concentration of sialic acid. A decrease in intestinal sialomucins was observed ${ }^{16}$ in rats drinking a solution containing tea catechins at $0.5 \%$.

These modifications on mucin composition generated with GE intake might be related to the changes observed on Escherichia coli and lactic bacteria populations. Changes in the chemical composition of intestinal mucins have been detected in response to alterations of gut microbiota. ${ }^{11}$ Recently, a link between intestinal sialic acid and the overgrowth of Enterobacteriaceae such as E. coli and Salmonella has been reported..$^{70}$ The ability to use sialic acid confers an advantage to several bacteria, as E. coli, to overgrowth. The lower Enterobacteriaceae counts obtained in the present study in the chickens fed the highest concentration of GE ( $5 \mathrm{~g} \mathrm{~kg}^{-1}$ of feed) may be related to the reduction in the proportion of sialic acid mucins.

Villus length and crypt depth are markers of intestinal functionality widely used by animal nutritionists. Changes in intestinal morphology may influence nutrient absorption and animal performance. It is assumed that a lengthening of villi leads to an improvement of digestive and absorptive functions in the intestine and to an increased body weight gain. ${ }^{71}$ Despite this, few reports have documented the effect of dietary polyphenols or related phenolics on the intestinal morphology and function and on the impact of these effects on broiler chicken performance. While Sell et al. ${ }^{72}$ did not find any adverse effect of condensed tannins from sorghum on the intestinal tract morphology of chickens or laying hens, tannins from faba beans caused atrophy and shortening of villi in chickens in a further study. ${ }^{73}$ Regarding the effects of grape polyphenols, we previously reported ${ }^{18}$ a positive response on villus length in broiler chickens fed GP but shorter villi and shallower crypts, in parallel with a reduction (by $12 \%$ ) of weight gain, were found in birds fed a high amount $\left(7.2 \mathrm{~g} \mathrm{~kg}^{-1}\right)$ of GE. In the present study, feeding $5 \mathrm{~g} \mathrm{~kg}^{-1}$ of GE had no effect on the intestinal morphology of broiler chickens. Other authors ${ }^{69}$ reported an increase in villus height in heat-exposed broiler chickens with doses of GE as low as $0.15-0.45 \mathrm{~g} \mathrm{~kg}^{-1}$. Differences among studies in the amount provided and in the composition of the GE tested, as well as in the health status of chickens, may explain such discrepancies. Advances in the knowledge of the interactions between bioactive feed compounds with intestinal barrier traits and luminal microbial environment could contribute to a better understanding of both positive and negative effects of GE on growth performance and intestinal functionality and on its practicality in animal nutrition.

\section{Conclusions}

The results of the current study confirm that an important proportion of the ingested grape catechins disappear and/or are chemically modified throughout the intestinal tract of chickens, and consequently are recovered at a low rate. The digestibility of grape catechins is reduced with an increasing degree of polymerization and with gallic acid esterification. The identification of microbial-derived phenolic metabolites in the chicken excreta confirms that a portion of the ingested grape polyphenols is used by intestinal microbiota, which affects the composition of microbial populations and the type of intestinal mucins.

\section{Abbreviations}

$\begin{array}{ll}\text { GE } & \text { Grape extract } \\ \text { GP } & \text { Grape pomace } \\ \text { C } & \text { Catechin } \\ \text { EC } & \text { Epicatechin } \\ \text { ECG } & \text { Epicatechin-O-gallate } \\ \text { PB1 } & \text { Procyanidin dimer B1 } \\ \text { PB2 } & \text { Procyanidin dimer B2 } \\ \text { GA } & \text { Gallic acid } \\ \text { BCIG } & \text { 5-Bromo-4-chloro-3-indolyl-beta-D-glucoronide } \\ \text { IM } & \text { Indigestible marker } \\ \text { GPol } & \text { Grape polyphenols }\end{array}$




\section{Conflicts of interest}

There are no conflicts of interest to declare.

\section{Acknowledgements}

The authors wish to thank the Spanish Ministry of Economy and Competitiveness (MINECO, Spain AGL2012-31355) and Junta de Castilla y León (UCA304U13) for the financial support of this investigation. We acknowledge support of the publication fee by the CSIC Open Access Publication Support Initiative through its Unit of Information Resources for Research (URICI).

\section{References}

1 G. R. Beecher, Proanthocyanidins: biological activities associated with human health, Pharm. Biol., 2004, 42, 2.

2 A. P. Neilson and M. G. Ferruzzi, Influence of formulation and processing on absorption and metabolism of flavan-3ols from tea and cocoa, Annu. Rev. Food Sci. Technol., 2011, $2,125$.

3 A. Brenes, A. Viveros, S. Chamorro and I. Arija, Use of polyphenol-rich grape by-products in monogastric nutrition. A review, Anim. Feed Sci. Technol., 2016, 211, 1.

4 S. Chamorro, A. Viveros, C. Centeno, C. Romero, I. Arija and A. Brenes, Effects of dietary grape seed extract on growth performance, amino acid digestibility and plasma lipids and mineral content in broiler chicks, Animal, 2013, $7,555$.

5 S. Chamorro, A. Viveros, A. Rebolé, I. Arija, C. Romero, I. Alvarez, A. Rey and A. Brenes, Addition of exogenous enzymes to diets containing grape pomace: Effects on intestinal utilization of catechins and antioxidant status of chickens, Food Res. Int., 2017, 96, 226.

6 J. L. Donovan, K. S. Kasim-Karakas, J. B. German, R. L. Walzem, R. J. Hansen and A. L. Waterhouse, Urinary excretion of catechin metabolites by human subjects after red wine consumption, Br. J. Nutr., 2002, 87, 31.

7 C. Tsang, C. Auger, W. Mullen, A. Bornet, M. Rouanet, A. Crozier and P. L. Teissedre, The absorption, metabolism and excretion of flavan-3-ols and procyanidins following the ingestion of a grape seed extract by rats, Br. J. Nutr., 2005, 94, 170.

8 M. P. Gonthier, J. L. Donovan, O. Texier, C. Felgines, C. Remesy and A. Scalbert, Metabolism of dietary procyanidins in rats, Free Radical Biol. Med., 2003, 35, 837.

9 F. Sánchez-Patán, C. Cueva, M. Monagas, G. E. Walton, G. R. Gibson, P. J. Martin-Suarez, M. V. Moreno-Arribas and B. Bartolome, Gut microbial catabolism of grape seed flavan-3-ols by human faecal microbiota. Targetted analysis of precursor compounds, intermediate metabolites and end-products, Food Chem., 2012, 131, 337.
10 J. A. Clark, S. M. Doelle, M. D. Halpern, T. A. Saunders, H. Holubec, K. Dvorak, S. A. Boitano and B. Dvorak, Intestinal barrier failure during experimental necrotizing enterocolitis: protective effect of EGF treatment, Am. J. Physiol. Gastrointest. Liver Physiol., 2006, 291, 938.

11 B. Deplancke and H. R. Gaskins, Microbial modulation of innate defense: goblet cells and the intestinal mucus layer, J. Clin. Nutr., 2001, 73, 1131S.

12 K. Yamauchi, T. Buwjoom, K. Koge and T. Ebashi, Histological alterations of the intestinal villi and epithelial cells in chickens fed dietary sugar cane extract, Br. Poult. Sci., 2006, 47, 544.

13 A. Smirnov, R. Perez, E. Amit-Romach, D. Sklan and Z. Uni, Mucin dynamics and microbial populations in chicken small intestine are changed by dietary probiotic and antibiotic growth promoter supplementation, J. Nutr., 2005, 135, 187.

14 S. Hino, N. Takemura, K. Sonoyama, A. Morita, H. Kawagishi, S. Aoe and T. Morita, Small intestinal goblet cell proliferation induced by ingestion of soluble and insoluble dietary fiber is characterized by an increase in sialylated mucins in rats, J. Nutr., 2012, 142, 1429.

15 A. Barcelo, J. Claustre, F. Moro, J. Chayvialle, J. Cuber and P. Plaisancie, Mucin secretion is modulated by luminal factors in the isolated vascularly perfused rat colon, Gut, 2000, 46, 218.

16 Y. Ito, T. Ichikawa, T. Iwai, Y. Saegusa, T. Ikezagua, Y. Goso and K. Ishihara, Effects of tea catechins on the gastrointestinal mucosa in rats, J. Agric. Food Chem., 2008, 56, 12122.

17 A. Brenes, A. Viveros, I. Goñi, C. Centeno, S. G. SayagoAyerdi and I. Arija, Effect of grape pomace concentrate and vitamin $\mathrm{E}$ on digestibility of polyphenols and antioxidant activity in chickens, Poult. Sci., 2008, 87, 307.

18 A. Viveros, S. Chamorro, M. Pizarro, I. Arija, C. Centeno and A. Brenes, Effects of dietary polyphenol-rich grape products on intestinal microflora and gut morphology in broiler chicks, Poult. Sci., 2011, 90, 566.

19 S. Chamorro, A. Viveros, A. Rebolé, A. Rica, I. Arija and A. Brenes, Influence of dietary enzyme addition on polyphenol utilization and meat lipid oxidation of chicks fed grape pomace, Food Res. Int., 2015, 73, 197.

20 S. Chamorro, I. Goñi, A. Viveros, D. Hervert-Hernandez and A. Brenes, Changes in polyphenolic content and antioxidant activity after thermal treatments of grape seed extract and grape pomace, Eur. Food Res. Technol., 2012, 234, 147.

21 National Research Council, Nutrient Requirements of Poultry, Natl. Acad. Press, Washington, DC, 9th rev. ed., 1994.

22 F. Sánchez-Patán, M. Monagas, M. V. Moreno-Arribas and B. Bartolome, Determination of microbial phenolic acids in human feces by UPLC-ESI-TQ MS, J. Agric. Food Chem., 2011, 59, 2241.

23 I. Muñoz-González, A. Jiménez-Girón, P. J. Martín-Álvarez, B. Bartolomé and M. V. Moreno-Arribas, Profiling of 
microbial-derived phenolic metabolites in human feces after moderate red wine intake, J. Agric. Food Chem., 2013, 61, 9470.

24 P. Siriwan, W. L. Bryden, Y. Mollah and E. F. Annison, Measurement of endogenous amino acid losses in poultry, Br. Poult. Sci., 1993, 34, 939.

25 C. Romero, N. Nicodemus, J. D. Rodríguez, A. I. García and C. de Blas, Effect of type of grinding of barley and dehydrated alfalfa on performance, digestion, and crude mucin ileal concentration in growing rabbits, J. Anim. Sci., 2011, 89, 2472.

26 K. A. Lien, W. C. Sauer and M. Fenton, Mucin output in ileal digesta of pigs fed a protein-free diet, $Z$. Ernährungswiss., 1997, 36, 182.

27 N. L. Horn, S. S. Donkin, T. J. Applegate and O. Adeola, Intestinal mucin dynamics: Response of broilers chicks and White Pekin ducklings to dietary threonine, Poult. Sci., 2009, 88, 1906.

28 R. Schauer, Characterization of sialic acids, Methods Enzymol., 1978, 50, 64.

29 SAS Institute, SAS Stat user's guide, Version 8th edition, SAS institute Inc., Cary, NC, USA, 2003.

30 A. J. M. Jansman, J. Huisman and A. F. B. van der Poel, Faba bean with different tannin contents: ileal and faecal digestibility in piglets and growth in chicks, in Recent advances in research of antinutritional factors in legume seeds, ed. J. Huisman, A. F. B. van der Poel and I. E. Liener, Pudoc, Wageningen, The Netherlands, 1989, p. 176.

31 L. T. Ortiz, C. Centeno and J. Treviño, Tannins in faba bean seeds: effects on the digestion of protein and amino acids in growing chicks, Anim. Feed Sci. Technol., 1993, 41, 271.

32 C. M. Nyachoti, J. L. Atkinson and S. Leeson, Sorghum tannins: a review, World's Poult. Sci. J., 1997, 53, 5.

33 A. Brenes, A. Viveros, I. Goñi, C. Centeno, F. Saura-Calixto and I. Arija, Effect of grape seed extract on growth performance, protein and polyphenol digestibilities, and antioxidant activity in chickens, Span. J. Agric. Res., 2010, 8, 326.

34 I. Goñi, A. Brenes, C. Centeno, A. Viveros, F. Saura-Calixto, A. Rebolé, I. Arija and R. Esteve, Effect of dietary grape pomace and vitamin $\mathrm{E}$ on growth performance, nutrient digestibility and susceptibility to meat lipid oxidation in chickens, Poult. Sci., 2007, 86, 508.

35 A. M. Gonzalez-Paramás, S. Esteban-Ruano, C. SantosBuelga, S. de Pascual-Teresa and J. C. Rivas-Gonzalo, Flavanol content and antioxidant activity in winery products, J. Agric. Food Chem., 2004, 52, 234.

36 Y. Yilmaz and R. T. Toledo, Major flavonoids in grape seeds and skins: Antioxidant capacity of catechin, epicatechin, and gallic acid, J. Agric. Food Chem., 2004, 52, 255.

37 C. Auger, W. Mullen, Y. Hara and A. Crozier, Bioavailability of polyphenon E flavan-3-ols in humans with ileostomy, J. Nutr., 2008, 138, 1535S.

38 G. Borges, M. E. Lean, S. A. Roberts and A. Crozier, Bioavailability of dietary (poly)phenols: a study with ileos- tomists to discriminate between absorption in small and large intestine, Food Funct., 2013, 4, 754.

39 C. Manach, A. Scalbert, C. Morand, C. Rémésy and L. Jiménez, Polyphenols: Food sources and bioavailability, Am. J. Clin. Nutr., 2004, 79, 727.

40 S. M. Henning, J. J. Cho and D. Heber, Nongallated compared with gallated flavan-3-ols in green and black tea are more bioavailable, J. Nutr., 2008, 138, 1529S.

41 A. Stalmach, W. Mullen, H. Steilling, G. Willliamson, M. E. J. Lean and A. Crozier, Absorption, metabolism, and excretion of green tea flñavan-3-ols in humans with an ileostomy, Mol. Nutr. Food Res., 2010, 54, 323.

42 L. Actis-Goretta, A. Leveques, M. Rein, A. Teml, C. Schäfer, U. Hofmann, H. Li, M. Schwab, M. Eichelbaum and G. Williamson, Intestinal absorption, metabolism, and excretion of (-)-epicatechin in healthy humans assessed by using an intestinal perfusion technique, Am. J. Clin. Nutr., 2013, 98, 924.

43 M. Monagas, M. Urpi-Sarda, F. Sanchez-Patan, R. Llorach, I. Garrido, C. Gómez-Cordovés, C. Andres-Lacueva and B. Bartolomé, Insights into the metabolism and microbial biotransformation of dietary flavan-3-ols and the bioactivity of their metabolites, Food Funct., 2010, 1, 233.

44 A. Crozier, Dietary polyphenolics, absorption, mammalian and microbial metabolism and colonic health, Mol. Nutr. Food Res., 2009, 53, S5.

45 A. S. Hole, I. Rud, S. Grimmer, S. Sigl, J. Narvhus and S. Sahlstrøm, Improved bioavailability of dietary phenolic acids in whole grain barley and oat groat following fermentation with probiotic Lactobacillus acidophilus, Lactobacillus johnsonii, and Lactobacillus reuteri, J. Agric. Food Chem., 2012, 60, 6369.

46 M. V. Selma, J. C. Espin and F. A. Tomás-Barberán, Interaction between phenolic and gut microbiota: role in human health, J. Agric. Food Chem., 2009, 57, 6485.

47 J. A. Rothwell, J. Pérez-Jiménez, V. Neveu, A. Medina-Ramon, N. M'Hiri, P. Garcia Lobato, C. Manach, K. Knox, R. Eisner, D. Wishart and A. Scalbert, Phenol-Explorer 3.0: a major update of the Phenol-Explorer database to incorporate data on the effects of food processing on polyphenol content, Database, 2013, bat070.

48 M. M. Appeldoorn, J. P. Vincken, A. M. Aura, P. C. H. Hollman and H. Gruppen, Procyanidin dimers are metabolized by human microbiota with 2-(3,4Dihydroxyphenyl) acetic acid and 5-(3,4-Dihydroxyphenyl)$\gamma$-valerolactone as the major metabolites, J. Agric. Food Chem., 2009, 57, 1084.

49 G. Groenewoud and H. K. L. Hundt, The microbial metabolism of condensed $(+)$-catechins by rat-caecal microflora, Xenobiotica, 1986, 16, 99.

50 S. Deprez, C. Brezillon, S. Rabot, C. Philippe, I. Mila, C. Lapierre and A. Scalbert, Polymeric proanthocyanidins are catabolized by a human colonic microflora into low molecular weight phenolic compounds, J. Nutr., 2000, 130, 2733.

51 F. Sánchez-Patán, C. Cueva, M. Monagas, G. E. Walton, G. R. Gibson, J. E. Quintanilla-López, R. Lebrón-Aguilar, 
P. J. Martín-Álvarez, M. V. Moreno-Arribas and B. Bartolomé, In vitro fermentation of a red wine extract by human gut microbiota: Changes in microbial groups and formation of phenolic metabolites, J. Agric. Food Chem., 2012, 60, 2136.

52 S. Touriño, J. Pérez-Jiménez, M. Mateos-Martin, E. Fuguet, M. P. Vinardell, M. Cascante and J. L. Torres, Metabolites in contact with the rat digestive tract after ingestion of a phenolic-rich dietary fiber matrix, J. Agric. Food Chem., 2011, 59, 5955.

53 M. Urpi-Sarda, M. Monagas, N. Khan, R. Llorach, R. M. Lamuela-Raventós, O. Jáuregui, R. Estruch, M. Izquierdo-Pulido and C. Andrés-Lacueva, Targeted metabolic profiling of phenolics in urine and plasma after regular consumption of cocoa by liquid chromatography-tandem mass spectrometry, J. Chromatogr. A, 2009, 1216, 7258.

54 N. C. Ward, K. D. Croft, J. B. Puddey and J. M. Hodgson, Supplementation with grape seed polyphenols results in increased urinary excretion of 3-hydroxyphenylpropionic acid, an important metabolite of proanthocyanidins in humans, J. Agric. Food Chem., 2004, 52, 5545.

55 M. Margalef, Z. Pons, F. I. Bravo and A. Arola-Arnal, Plasma kinetics and microbial biotransformation of grape seed flavanols in rats, J. Funct. Foods, 2015, 12, 478.

56 M. Monagas, I. Garrido, R. Lebron-Aguilar, M. C. GomezCordoves, A. Rybarczyk, R. Amarowicz and B. Bartolome, Comparative flavan-3-ol profile and antioxidant capacity of roasted peanut, hazelnut, and almond skins, J. Agric. Food Chem., 2009, 57, 10590.

57 I. B. Jaganath, W. Mullen, M. E. J. Lean, C. A. Edwards and A. Crozier, In vitro catabolism of rutin by human fecal bacteria and the antioxidant capacity of its catabolites, Free Radical Biol. Med., 2009, 29, 1180.

58 J. M. Laparra and Y. Sanz, Interactions of gut microbiota with functional food components and nutraceuticals, Pharmacol. Rev., 2010, 61, 219.

59 F. Cardona, C. Andrés-Lacueva, S. Tulipani, F. J. Tinahones and M. I. Queipo-Ortuño, Benefits of polyphenols on gut microbiota and implications in human health, J. Nutr. Biochem., 2013, 24, 1415.

60 A. Braune and M. Blaut, Bacterial species involved in the conversion of dietary flavonoids in the human gut, Gut Microbes, 2016, 7, 216.

61 G. Özkan, O. Sagdiç, N. G. Baydar and Z. Kurumahmutoglu, Antibacterial activities and total phenolic contents of grape pomace extracts, J. Sci. Food Agric., 2004, 84, 1807.

62 P. Dolara, C. Luceri, C. De Filippo, A. P. Femia, L. Giovannelli, G. Caderni, C. Cecchini, S. Silvi, C. Orpianesi and A. Cresci, Red wine polyphenols influence carcinogenesis, intestinal microflora, oxidative damage and gene expression profiles of colonic mucosa in F344 rats, Mutat. Res., 2005, 591, 237.

63 H. C. Lee, A. M. Jenner, C. S. Low and Y. K. Lee, Effect of tea phenolics and their aromatic fecal bacterial metabolites on intestinal microbiota, Res. Microbiol., 2006, 157, 876.

64 N. Alakomih, R. Puuponen-Pimia, A. M. Aura, I. M. Helander, L. Nohynek, K. M. Oksman-Caldentey and M. Saarela, Weakening of salmonella with selected microbial metabolites of berry-derived phenolic compounds and organic acids, J. Agric. Food Chem., 2007, 55, 3905.

65 D. Hervert-Hernández, C. Pintado, R. Rotger and I. Goñi, Stimulatory role of grape pomace polyphenols on Lactobacillus acidophilus growth, Int. J. Food Microbiol., 2009, 136, 119.

66 I. Moreno-Indias, L. Sánchez-Alcoholado, P. PérezMartínez, C. Andrés-Lacueva, F. Cardona, F. Tinahones and M. I. Queipo-Ortuño, Red wine polyphenols modulate fecal microbiota and reduce markers of the metabolic syndrome in obese patients, Food Funct., 2016, 7, 1775.

67 R. Verhelst, M. Schroyen, N. Buys and T. Niewold, Dietary polyphenols reduce diarrhea in enterotoxigenic Escherichia coli (ETEC) infected post-weaning piglets, Livest. Sci., 2014, 160, 138.

68 A. Fiesel, D. K. Gessner, E. Most and K. Eder, Effects of dietary polyphenol-rich plant products from grape or hop on pro-inflammatory gene expression in the intestine, nutrient digestibility and faecal microbiota of weaned pigs, BMC Vet. Res., 2014, 10, 196.

69 H. Hajati, A. Hassanabadi, A. G. Golian, H. NassiriMoghaddam and M. R. Nassiri, The effect of grape seed extract and vitamin $\mathrm{C}$ feed supplements carcass characteristics, gut morphology and ileal microflora in broiler chickens exposed to chronic heat stress, Iran. J. Appl. Anim. Sci., 2015, 5, 155.

70 Y. L. Huang, C. Chassard, M. Hausmann, M. von Itzstein and T. Hennet, Sialic acid catabolism drives intestinal inflammation and microbial dysbiosis in mice, Nat. Commun., 2015, 6, 8141.

71 W. F. Caspary, Physiology and pathophysiology of intestinal absorption, Am. J. Clin. Nutr., 1992, 55, 299 S.

72 D. R. Sell, W. M. Reed, C. J. Chrisman and J. C. Rogler, Mucin excretion and morphology of the intestinal tract as influenced by sorghum tannins, Nutr. Rep. Int., 1985, 31, 1369.

73 L. T. Ortiz, C. Alzueta, J. Treviño and M. Castaño, Effects of faba bean tannins on the growth and histological structure of the intestinal tract and liver of chicks and rats, Br. Poult. Sci., 1994, 35, 743. 